Abstract 1605 Table 1 Tumor Characteristics

\begin{tabular}{|c|c|c|c|c|c|}
\hline Patient & 1 & 2 & 3 & 4 & 5 \\
\hline Size $(\mathrm{cm})$ & $1.5 \times 1.4 \times 1.1$ & $1.0 \times 1.0$ & $0.7 \times 0.6 \times 0.6$ & $1.3 \times 1.3 \times 0.5$ & $2.5 \times 2.0 \times 1.3$ \\
\hline Descriptive Characteristics & $\begin{array}{l}\text { Solitary, Non-mobile mass, } \\
\text { Irregular, firm, fixed }\end{array}$ & No mention in records & $\begin{array}{l}\text { Solitary, Non-mobile mass, Firm, } \\
\text { fleshy }\end{array}$ & $\begin{array}{l}\text { Solitary, Non-mobile mass, Soft, } \\
\text { well-circumscribed }\end{array}$ & $\begin{array}{l}\text { Solitary, Non-mobile mass, } \\
\text { Multi-lobulated }\end{array}$ \\
\hline Deep Structures Involved? & $\begin{array}{l}\text { Adherent to deltoid fascia and } \\
\text { muscle }\end{array}$ & No mention in records & $\begin{array}{l}\text { Portion of orbicularis oculi, } \\
\text { corrugator }\end{array}$ & No mention in records & No \\
\hline Margins & Well-defined & No mention in records & Well-defined & Well-defined & No mention in records \\
\hline
\end{tabular}

T Shadmanov, H Alimova. Republican Research Centre of Emergency Medicine, Tashkent, Uzbekistan

Background and Aims Bone grafting to replace missing bone with synthetic porous Biomaterial (i.e. bone graft scaffolds) and associated new bone formation and remodelling, have been investigated for over 30 years [Hing K., 2005]. Limited availability of autografts and the risk of disease transfer of allografts, however, has produced an increase in requests for synthetic bone grafts. This study estimate the osteogenic effects of white marble (powder).

Methods A bone defect $2.5 \mathrm{~mm}$ in diameter and $2 \mathrm{~mm}$ deep was made in the diaphysial part of femoral bone of male Wistar rats. The defects were filled with white marble powder (WM) and autogenous blood clot (control). The animals were euthanized 7, 15, 30, 60 and 90 days after surgery, and specimens were collected for radiographic and microscopic analyses. The bone defects were processed for paraffin embedding and $\mathrm{H} \& \mathrm{E}$ staining.

Results X-ray after the operation did not reveal obvious evidence of angiogenesis in the femoral condyles, where the X-ray density underwent slight changes. The optical density decreased significantly after the implantation, and the quantity of the osteoid, woven and lamellar bone increased in the bone tissue with time. The osteogenesis area with H\&E staining showed obvious bone formation, which was significantly different from the control group.

Conclusion Although osteo-conductive activity was not shown, the dolomite favored the repair process, compared to the control group. This study has shown that the white marble powder can be used as a graft to a small cortical bone defect.

\section{THE ROLE OF TRANSTHORACIC ULTRASOUNDS TO ASSESS PATIENTS WITH PECTUS EXCAVATUM}

doi:10.1136/archdischild-2012-302724.1608

N Zampieri, F Laconi, G Scire, A Mantovani, F Camoglio. Department of Surgical Sciences, Pediatric Surgical Unit, University of Verona, Policlincio G.B. Rossi, Verona, Italy

Introduction Pectus excavatum is the most common congenital malformation of the anterior chest wall; the purpose of this study is to assess the role of thoracic ultrasounds in the preoperative workup of patients affected by pectus excavatum

Materials and Methods An observational study was carried out ibetween january and september 2011. patients aged between 4 and 14 years of age were divided into 4 study groups. group a: healthy patients without pectus excavatum; group b: healthy patients with different grades of untreated pectus excavatum; group c: patients with pectus excavatum treated with nuss bar; group d: patients surgically treated with removed bar.

Results Patients with deeper anatomical depression showed a differential value between inspiration and expiration lower than healthy patients or patients with shallower depression $(p<0.05)$ in any age range considered; a depression deeper than $2.8 \mathrm{~cm}$ was associated with lower elasticity of the chest wall; chest dynamicity of patients treated with open techniques showed almost immobility of the parasternal region, with a differential value close to zero, and a differential value inferior to $0.5 \mathrm{~cm}$ at the level of the anterior axillary line.

Conclusions Study results confirm that the use of ultrasounds should be introduced as a standard preliminary test. patients with pectus excavatum have altered chest dynamicity if compared to healthy patients.

The study also confirms that the most suitable area of the chest for bar insertion in terms of dynamicity is between the fourth and sixth intercostal space: not necessarily near the deepest point of depression.

\section{NEW AMAZING TWO LATERAL CISOR LINE TECHNIC WITH DUAL MESH REPAIR IN OMPHALOCELE}

doi:10.1136/archdischild-2012-302724.1609

M Vali, R Ghaffari, A Macooie, Z Fakoor, S Geibi, S Hijazi, M Noruzi, H Ghaffari, M Ebrahimzadeh, M Jariani, A Ghaffari, K Ghaffari, AR Ghaffari, M Falaki, R Falaki, D Mahmoodzadeh, D Nikkibakhsh, D Karmyar, D Sadegi, D Gazavi, D Radvar, D Khosroshahi. Medical Science of Urmia, Urmia, Iran

Omphalocele is very disturbing problem in infants with more complication and trouble theraphy that the lesion covered with nylon paper and late repair. This problem so exposed very difficult management and therapy TPN and the intestine are exposed long time out of abdomen and nylon covered can teared so patients stayed long time in hospital.so presentation of new technic with early repair and soft cover is nessessary. For this from 3yrs ago the 10 neonate are surgeried with dual mesh.with initial repair of omphalocele in supine position that one edge of foam like mesh is sutured to abdominal wall and other soft edge overlied omphalocele contents with skin flap covered all them finally and two lateral cisor was done and in 1-3 yrs f/u the all 10 neonate that the oldest 3yrs old and youngest $6 \mathrm{mo}$ old nowadays are in health. This way is easy, safe with less TPN and hospital staying and more best results. The dual mesh was been same with abdominal wall without any complication. The study was done prospective and with dual mesh and CT scan 16 slice in control of them was done. The dual mesh was been same with abdominal wall.

\section{SYSTEMIC EFFECTS OF RETINOPATHY OF PREMATURITY SCREENING}

doi:10.1136/archdischild-2012-302724.1610

D Engür, F Cengiz Erdem, H Oğrağ, S Dündar, M Kaynak Türkmen. Adnan Menderes University, Aydin, Turkey

Background and Aims Examination for retinopathy of prematurity $(\mathrm{ROP})$ is one of the most painful procedures performed in neonatal intensive care units (NICU). In order to avoid severe visual impairment all infants below $1500 \mathrm{~g}$ and 32 th gestational age should be screened. The aim of this study is to identify the systemic effects and complications of mydriatic eye drops and the physical manipulation of the globe.

Methods The study sample included all preterm infants who were screened for ROP weighing up to $1500 \mathrm{~g}$ at birth and hospitalized in Adnan Menderes University NICU from January 2011 through 